\title{
Artificial Immune System (AIS)-based Location Management Scheme in Mobile Cellular Networks
}

\author{
Sanjay Kumar Biswash ${ }^{1}$, Mahasweta Sarkar², Dhirendra Kumar Sharma ${ }^{3}$ \\ ${ }^{1}$ Department of Computer Science and Engineering, NIIT University, Neemrana, Rajasthan 301705 India. \\ Email: skbismu@gmail.com
}

${ }^{2}$ Department of Electrical and Computer Engineering, San Diego State University, San Diego, CA 92182, USA. Email: msarkar2@ mail.sdsu.edu

3Department of Computer Science and Engineering, Avantika University Ujjain, Madhya Pradesh 456006, India. Email:dhirendrasharmaism@gmail.com

\begin{abstract}
In this paper, we are proposing a bio-inspired location management (LM) technique for personal communication system (PSC). It is based on artificial immune system (AIS), with self-adaptation and self-updates attributes in order to perform the location management, and work helps to achieve the better quality of service (QoS) and quality of experience (QoE) for the mobile users. Here, we are suggesting a modified mobile switching center (MSC) architecture, and an adaptive self-modified location management procedure. The proposed mobile switching centre architecture has an advantage of rule-based and fact-based system to store the rules and fact related to location management procedure, and it shows the intelligent behavior of system. The mobile switching centre calculates the best method for location management and rule-base system trigged the rules to perform the techniques. The system stores the result (techniques for location management) in fact-base system for future use. The efficiency and effectiveness of the proposed techniques been analyzed, and it observed that the proposed system has $45-50 \%$ improvement in performance over the current location management techniques. Here, we are taking the performance parameters such as signaling cost, database update cost, overhead measurement, mobility management cost.
\end{abstract}

Index Terms-Artificial immune system, Cellular networks, Personal communication system, Location management, Mobility management. 


\section{INTRODUCTION}

The any-time-any-where communication with mobility is basic requirement for cellular networks, and it a challenging task for service providers. The researchers are working on pervasive network interface to provide the better service to the mobile subscriber. It is a mandatory condition for better QoS/QoE, and highly sophisticated challenge for the next generation networks. The mobile networking is one of possible solutions to archive the QoE / QoS in dynamic scenario; have several challenges related to performance [1-4,26].

The effective network management is one of major issue in personal communication system, and it is very technical with high mobility $[1,2]$. The cellular network performance is depends on networks availability and mobility management [3, 25]. The user's mobility deals by mobility management (MM), and it has two parts such as: handoff management (HM) and location management (LM). These techniques used to track mobile users (MU)/ user equipment (UE) within the service area (SA). The service are is divided in to several location area (LA) and cells[1,2]. The mobility management is essential for all cellular technologies like 3G, 4G, long term evolution (LTE) etc. In LTE, the mobility management entity (MME) is responsible for the network management (mobility management) function [4, 7-9], which connects a group of mobile user with base station (BS), and it is also managed by mobile switching center (MSC), where each cell has a unique cell identity. The MSC is responsible for location information, routing information, billing issue, services to UE [1]. The complete PCS architecture and its working can be found in $[1,2,10]$, and it is the traditional system for location management in cellular networks. In present-days, mobility management is not limited to access points (AP) and BS, it being explore to end-to-end mobility support and energy management [4]. 
Modern science is using animals behavioral for their research, and it introduces a new field as nature-inspired computing. It also used to solve complex problems of information and communication technology (ICT) [5-6]. Several type of networks such as, wireless sensor networks (WSN), cognitive radio (CR), mobile ad-hoc networks (MANET), and personal communication system (PCS) are using the nature-inspired computing to solve their complex issues such as, routing, resource allocation, optimization, reliability, and network related operations [5].

\section{RELATED WORKS}

With the development of wireless networks and associated-devices, researchers are motivated to enhance communication technologies, and looking forward on pervasive communication system. The user-devices must have unique network management, so that UE can avail better QoS and QoE $[2,5,19,21,28]$. The existing mobility management schemes are classify into two categories: tunnel-based schemes and routing-based schemes [9]. The most of mobility management techniques are proposed for individual users, and they are widely investigated by researcher and it reached to new hype, but actually Network Mobility (NEMO) performance is still very poor. To enhance the performance of the network mobility, researchers are working on device-mobility-interface techniques. In [2, 4], authors proposed a traditional technique for the location management, and it is globally used by $3 \mathrm{G}$ networks.

In the PCS, all coverage area is divides into cells. The mobile base station serves each cell and the group of cells called location area (LA). All base station (BS) of location areas are directly connects to the mobile stitching center (MSC) through physical links [1-4]. The connectivity 
between user equipment (UE) and BS is wireless. The cellular networks have two databases, to store the user information called: home location register (HLR) and visitor location register (VLR).The HLR maintains the records for its own users, and VLR keeps the information about visitor-users [1-2, 9]. With every movement, the mobile user may change the serving base stations. Then mobile users need a new registration with the new base station. The completed procedure of this technique can be found in $[1,2,4,10]$, and we care comparing our proposed scheme with the location management procedure of $[1,2]$.

The authors of [11], proposed a new mobility management scheme, it provide seamless connectivity and reliable execution of context-aware transactions during mobility of users, and it is a combination of different queuing models. They conducted various experiments in order to prove the effectiveness of proposed scheme. In [7], authors proposed a concept of group-based network roaming in proxy mobile IPv6 (PMIPv6) domain, and they are considering it for 6LoWPAN-based wireless body area networks. The PMIPv6 is a standard to manage the network-based mobility in all-IP networks [27]. Then, several mathematical formulations have proposed for the location management, and most of them related to cost analysis of mobility management [2]. The authors of [8], developed an approach of embedded Markov chain model to analyze the signaling cost for movement-based location management (MBLM) scheme in cellular network, and it is applicable for $4 \mathrm{G}$ and LTE network. Now, researcher found natureinspired system is also applicable in communication networks $[5,12]$. The working of naturebased networking is not limited to Ant system, Bee system, Swarm intelligence etc. In this paper, we are focusing on artificial immune system for location management. There are very limited work is available in the area of nature- based networks. In [6], author proposed a new mobility aware bio-inspired routing protocol for MANETs, they introduced a mobility aware-termite 
(MA-Termite) system using pheromone smoothing.

\subsection{The Artificial Immune System}

The Chordata phylum of animals has notochord; it is an important structure in vertebrate, and leads to have a strong immune system. The immune system has fundamental attributes of adaptability, distributed, robustness, and self-regulated (self-updated) according to the situations. These properties are managing by cells (smallest unit of living animal called). The cells make tissues, and organs. The immune system protects the body against form known and unknown diseases such as virus and bacteria attacks. The natural immune systems works as a defensesystem for body against pathogens, and this field of the study called artificial immune systems (AIS). To survive from the massive attack of different viruses/bacteria is complex procedure, thus the body need a unique flexible immune system. It should efficiently strong to neutralize the specific antigens. To enhance the performance of body immune system, a multilevel defense system is required, and it should have self-adaptive, upgradeable and generic behavior. Now days several researcher have been motivated from immune system behavior and applying its behavior over many complex issues such as fault detection and pattern recognition. In [22], author proposed constrains for immune system based paradigm, and it is basis on response principle of system. A new cell signal transfer prospective, cell interaction techniques, optimizations conditions are discussed in [23]. The authors of [24] proposed a new multiclass classifier based on immune system principles. The proposed work has a unique feature of classifier for embedded property with local feature selection. In [16], authors proposed an optimization technique for the RIFD based position system and they produced several results for the three-benchmark functions. In [24], they are indicating that proposed system performs better than other algorithms. In addition, a evaluation results is produced in [16], it can predict picking 
cart's position more accurately. The authors of [17] introduced a new sub-pixel mapping strategy based on immune system, and is used for the sub-pixel mapping in remote sensing imagery system. The AIS, is inspired by the immune system, has the powerful information processing capabilities such as clustering/classification, anomaly detection, optimization, and data mining.

\subsection{Motivation and Contributions}

There are several location management techniques are available in literature. Each of them has own advantage and demerits. Now, we are looking for robust, scalable, and pervasive location management scheme. The immune system is helpful to achieve this objective. The artificial immune system is a growing paradigm in computational intelligence $(\mathrm{CI})$ and it has several application domains, such as recognition, detection, elimination of foreign threats and non-selfentities. It has the ability to learn, update, upgrade, adaptation. The artificial immune system has unique feature of "ability to learn" and "self-adaptability". In this work, we are using these components for our research purpose. There are several location management techniques available with many pit falls, but none of them follows natural phenomena. The mobile users are seeking a robust, intelligence, adaptive and self-configurability mechanisms for location management. It is motivation for us to apply the immune system for location management in mobile cellular networks. Here we are introducing immune system based location management scheme for cellular networks and making following contributions.

A. We are introducing modified mobile switching centre architecture for location management. It contains rule-base techniques, fact-base system, and an inferring machine. This proposed architecture achieve better QoS and QoE for the mobile users. 
B. A new nature-inspired location management technique, and it follows the fundamental principal of artificial immune system. This technique has the properties of selfconfigurability and adaptation and shows the intelligent behavior for system.

C. A mathematical analysis and software based implementation for performances analysis.

D. The system adaptability and update-mechanism for (within the rule and fact based) for update the domain-knowledge.

Rest of the paper is organizing as follows. The artificial immune system for the location management is discussing in section 2. The proposed model formulation and constraints analysis is available in section 3. The performance analysis and result in section 4 . Section 5, for the conclusions of the work, and followed by references.

\section{ARTIFICIAL IMMUNE SYSTEM FOR LOCATION MANAGEMENT}

The proposed work has two parts: the modified mobile switching architecture and the location management procedure.

\subsection{The mobile switching centre architecture}

The self-healing and robust system mechanism is a fundamental part of immune system. Here, we are mapping these attributes with proposed MSC architecture. In consequence, we are introducing the rule-base system (RBS), fact-base system (FBS) and inferring machine (IM) system for mobile switching centre(as shown in figure 1). 


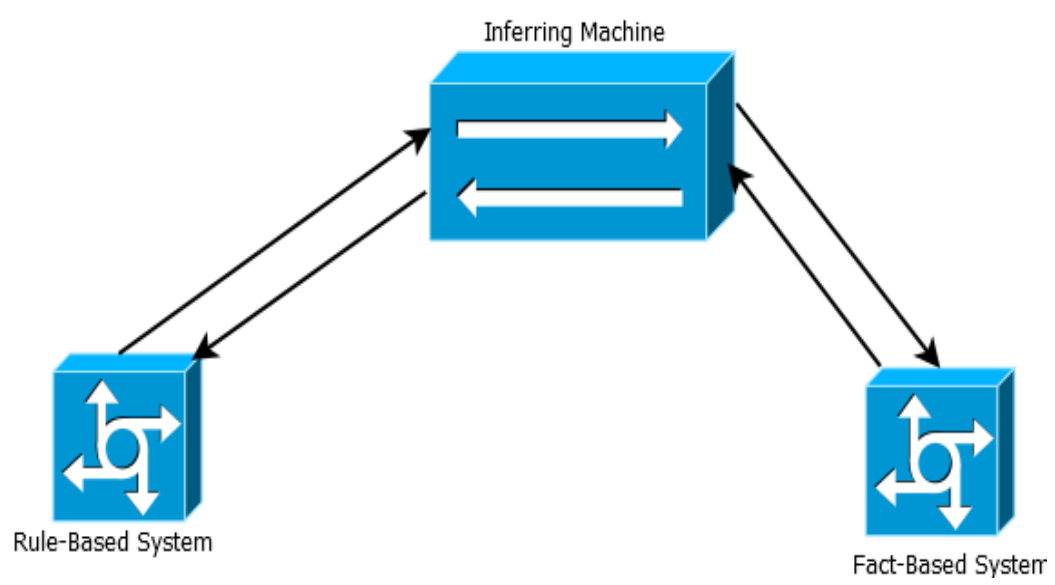

Figure 1: The Modified MSC Architecture

The RBS used to store all kinds of the rules associated with location management. If the mobile user is not residing in the native LA, then it needs a location update. It computes optimized least metrics based method for the location management. The fact-based system is responsible for of all kinds of fact, such as appropriate location management scheme for particular location. The inferring machine mapped the information between RBS and FBS. As per the availability of the new information in the system, the FBS and RBS are ready for self-update. For example, if there is any best method for LM (innovated by RBS). Then the FBS will overwrite this information and this mechanism lead to self-adaptability in AIS. The update mechanism is completely adaptive base and it is a scalable system.

\subsection{The LM Technique}

The natural systems are very simple and effective, and this behavior will use for research. It helps the people to solve the several complex challenges. In this decade, the natural behaviors are widely used and applicable to solve several issues of networking. In this work, we are using artificial intelligent system's behaviors. The artificial immune system automatically increases 
body resistance power, after the infections of virus or bacteria, and here we are using this strategy for location management procedure.

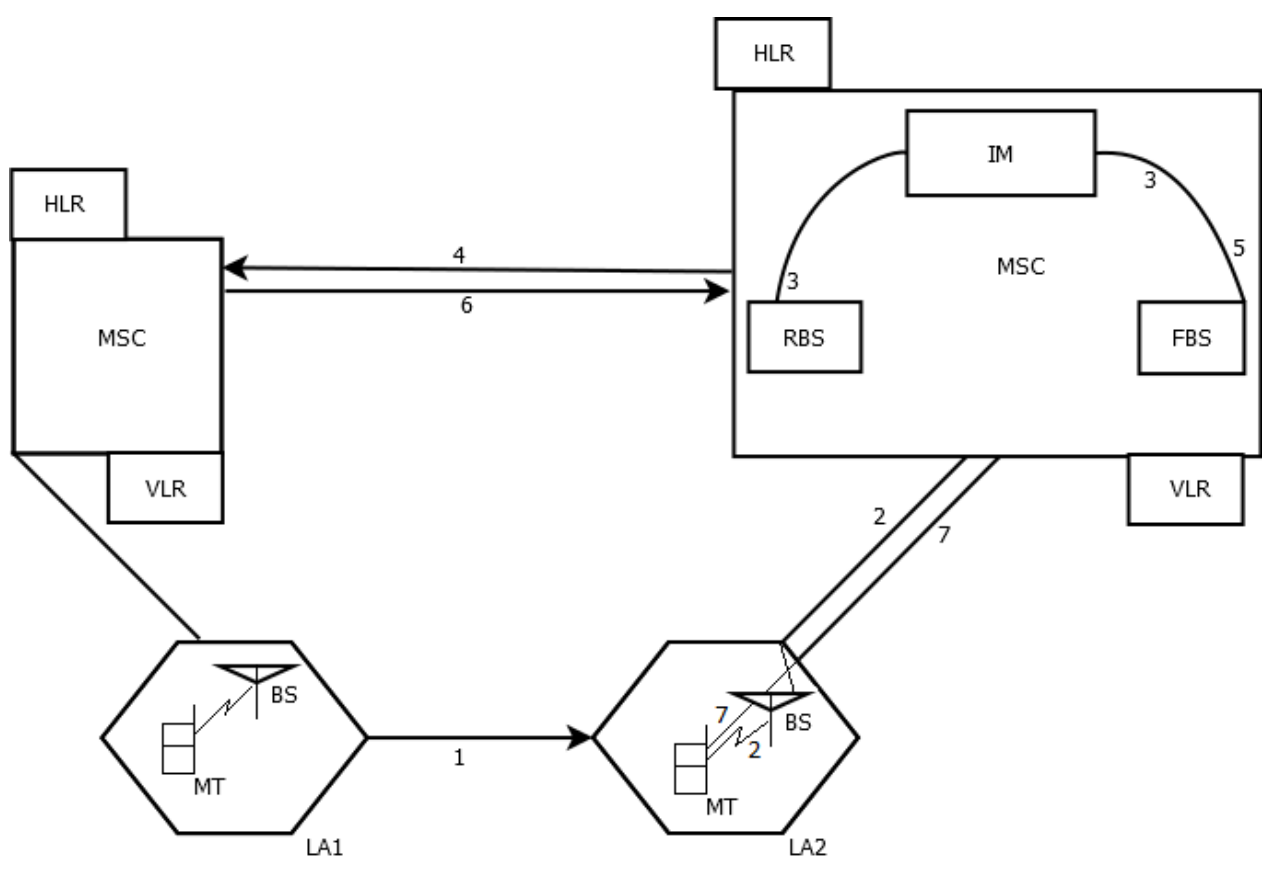

Figure 2: Artificial Immune System for Location Management

There are the following steps in proposed location management scheme, and they are shown in figure 2 .

1. The UE is moving from one LA to another LA. So, mobile user will go-through the location update procedure.

2. The mobile user sends the location update message to the serving BS, and BS forward it to the associated mobile switching centre.

3. The mobile switching centre checks the RBS for the particular movement of the user. 
4. If, there is a new movement, and there is no related information in RBS. Then, mobile switching centre will computes the best possible procedure to perform the location update.

5. If, location update information is available in FBS (by old location updates). Then, mobile switching centre fetches the corresponding rules from the RBS, and the FBS performs the location update procedure. After a successful location update, the procedure will be stored in the fact-based system for the future use.

6. The current mobile switching centre sends the de-registration message to old mobile switching centre and mobile user receives the acknowledgement message.

7. A successful registration message sends to mobile user.

\subsection{RBS and FBS update procedure}

The RBS and FBS update procedure is very important and it has following methodology. A new mobile user performs registration procedure with the above describe method (as mention in section 3.2), and then system will store the method for the other UE. If a new mobile user sends the location update request with the same circumstances (with reference to first mobile user), then the system will fetch the associated method from rule based system and performs the location update procedure.

Note: If a new unique and least cost/effort/metrics based procedure is available between source to destination, then system will go-through a self-update mechanism in FBS. It will be helpful for new user, and it shows an adaptive behavior of system. For example, if a mobile user request for location update from the location area\#1(LA1), and best method M1 is available in face based system. Then, the system will perform the location update with M1. After some time, system observed that there is another most favorable-method M2 available for LA\#1. Then the 
fact-based system will overwrite the M1 by M2 for better QoS/QoE.

\subsection{Illustration of procedure}

In this section, we are elaborating our work with example. We are assuming, there are four fact and their associated rules are available in fact-based and rule-based system, respectively (as shown in figure 3). The facts and rules are as: F1 to F4 and R1 to R4, respectively.

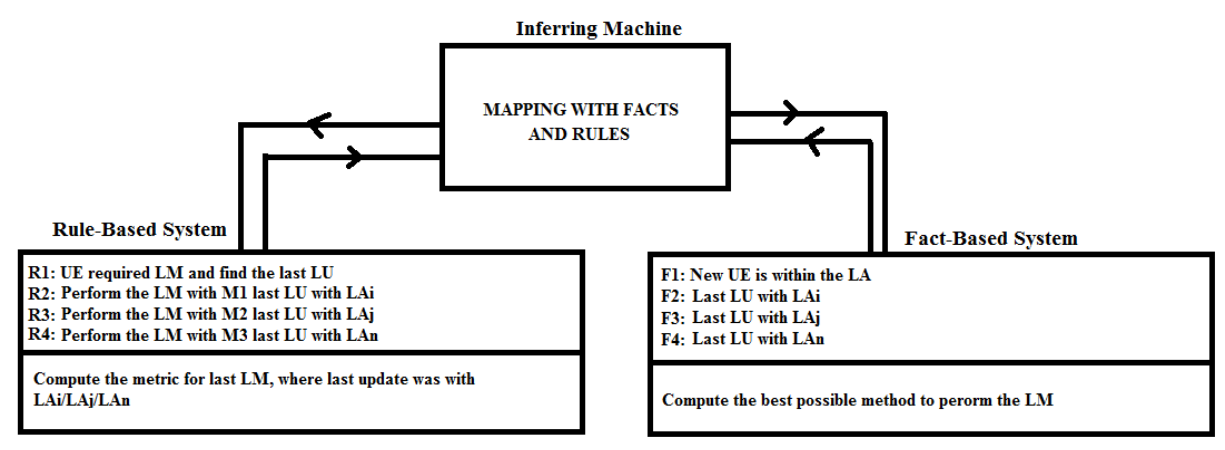

Figure 3: Illustration of the work

The UE moves out from the native location area and its need a location update. This procedure will initiate by network (self-insatiate). The request is receive by BS and forwarded to mobile switching centre. In the fact-based system, F1 will be active. Then, rule R1 will trig to perform the location management. The rule base system will find the last updated information, and according to its appropriate rules corresponding action is taken by RBS (as mention in R2, R2 and R3). It will inform to fact-based system, the facts will be stored for future reference, and it will used for other mobile users. This procedure will reduce the overheads for location update.

\section{MODEL FORMULATION}

In this section, we are formulating proposed location management scheme and using some mathematical notions (as describe in table 1). 


\begin{tabular}{|l|l|}
\hline \multicolumn{1}{|c|}{ Notation } & \multicolumn{1}{c|}{ Description } \\
\hline$v$ & The average speed of the UE. \\
\hline$\rho$ & The population density within a LA \\
\hline$L$ & The perimeter of the region $L$ \\
\hline$R_{\text {handoff }}$ & Rate of handoff \\
\hline$N$ & Number of LA in the service area \\
\hline$\pi$ & Steady state probability of the user in a LA \\
\hline$\pi_{O}^{O} / \pi_{O}^{V} / \pi_{V}^{V} / \pi_{V}^{O}$ & $\begin{array}{l}\text { Steady state probability for own LA to own LA/ visitor } \\
\text { LA. }\end{array}$ \\
\hline$R_{O}^{O} / R_{O}^{V} / R_{V}^{V} / R_{V}^{O}$ & $\begin{array}{l}\text { Handoff rate for own LA to own LA/ visitor LA to own } \\
\text { LA/ visitor LA to visitor LA/ own to visitor LA. }\end{array}$ \\
\hline$C_{M A T}$ & Cost of matching \\
\hline$C_{F A T}$ & Cost of fetching \\
\hline$C_{U P}$ & Cost of update \\
\hline $\mathrm{cL}$ & Expected cost per byte of loading \\
\hline $\mathrm{cU}$ & Expected cost per byte of update \\
\hline $\mathrm{Avg}(\mathrm{D})$ & Average number of data to be updated \\
\hline$C_{S I G N A L}$ & Signaling Cost \\
\hline$h$ & Number of hop between shortest paths. \\
\hline$N_{M T} / N_{C N}$ & Number of UE/ Corresponding node \\
\hline$\chi$ & Linear coefficient of LM \\
\hline$v$ & Per unit per association lookup cost \\
\hline$\eta$ & Proportionality constant \\
\hline $\mathrm{T}_{\mathrm{P}} / \mathrm{S}$ & Binding transmission cost. \\
\hline$\phi$ & \\
\hline
\end{tabular}

Table 1: Notation and Descriptions 
The mobility model has an important role to formulate the wireless networks, and most of the researcher are using random waypoint mobility model for this purpose. In the cellular networks, user-movement is a stochastic process, and it follows the random walk mobility $[1,2]$. To correlate the proposed work with random walk model, we are calculating all possible user movements. In the PCS network, the movement can be differentiating in the three levels, as follows.

CASE 1: Moves within the own LA.

CASE 2: Moves form own LA to adjacent LA.

CASE 3: Moves from the adjacent LA to own LA.

CASE 4: Moves from the adjacent LA to another new adjacent LA.

CASE 5: Moves from new adjacent LA to own LA.

CASE 6: Moves within the adjacent LA.

Now, we are formulating the Markov model with the associated movement-probability (as discussed above), and showing in figure 4 . Here, we are calculating the mobility pattern between three location areas, and it will repeat for all movements pattern. For example, if we consider seven-cell structure and applying mobility pattern then, it will same as three-LA movement, because the movement of user will always repeat the three LA systems.

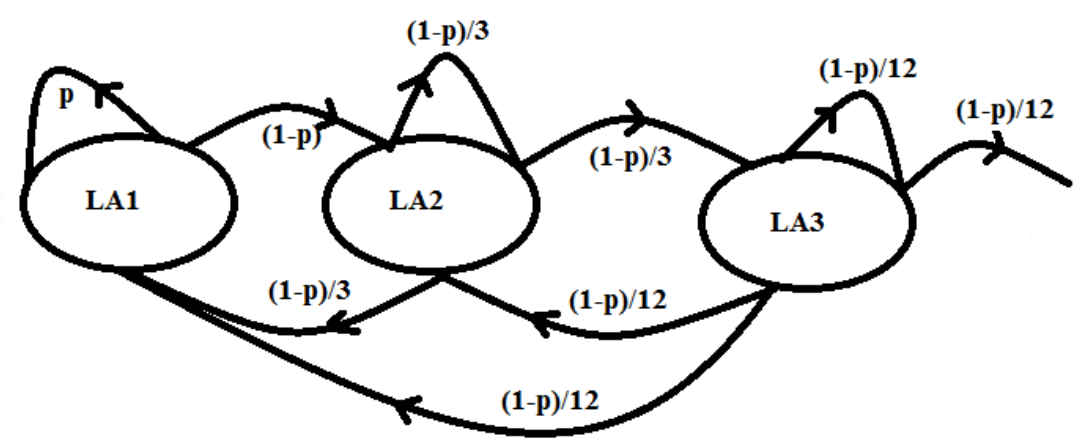

Figure 4: Markov Model for User Mobility 
The average speed of mobile user(v), and its direction is being measure with straight line, leading to center of the cell from the initial location of UE. The amount of traffic passing through this region is proportional to the population density $(\rho)$ with the region and perimeter L. The approximate number of boundary crossing: $\Omega=\frac{v \rho L}{\pi}[2]$. The possible handoff rate is $R_{\text {handoff }}=\frac{v \rho L}{\pi} N$, where $N$ is the number of location areas within the service area. The $\pi$ is steady state probability for UE, within a location area (own LA /adjacent LA). The usermovement pattern has four steady states, as shown in figure 5.

1. User is staying in a location area and make a movement within the own area.

2. User moves away from native location area reach to adjacent LA.

3. User is moving within the adjacent location area.

4. User is moving form adjacent location area to own native area.

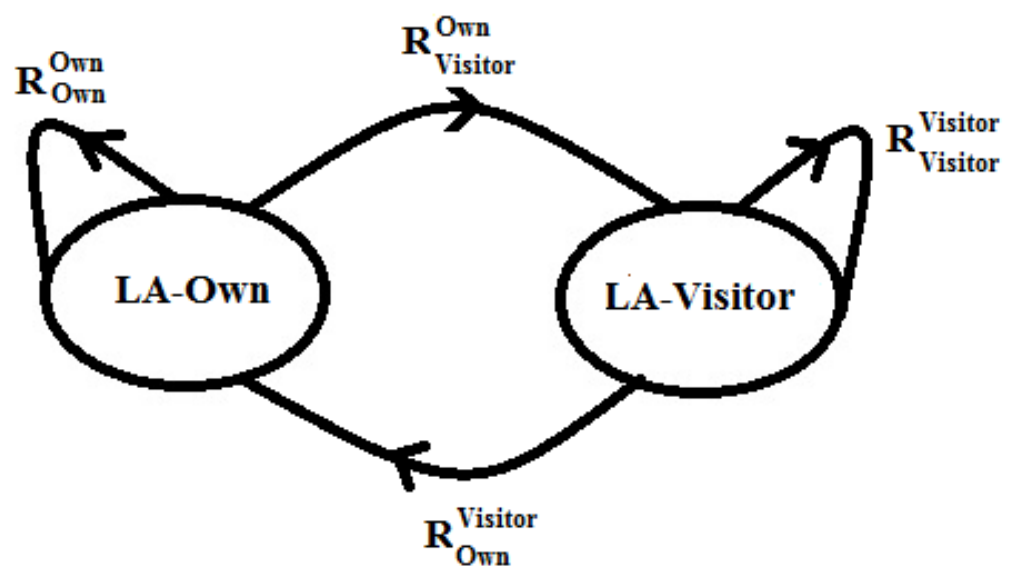

Figure 5: Markov Model for User's State Change

The steady states-associated-probabilities been calculated, and it is same as user's mobility.

$\operatorname{CASE} 1=\pi_{O}^{O}=\frac{R_{O}^{O}}{R_{O}^{O}+R_{V}^{O}}$ 
CASE $2=\pi_{V}^{O}=\frac{R_{V}^{O}}{R_{O}^{O}+R_{V}^{O}}$

CASE $4=\operatorname{CASE} 6=\pi_{V}^{V}=\frac{R_{V}^{V}}{R_{V}^{V}+R_{O}^{V}}$

CASE $3=\operatorname{CASE} 5=\pi_{O}^{V}=\frac{R_{O}^{V}}{R_{V}^{V}+R_{O}^{V}}$

The localization-probability $(p)$ is the probability of mobile user's, moves within the own location area, and the handoff rates are:

CASE 1: $\frac{v \rho L \times\left[R_{O}^{o}+R_{V}^{o}\right] \times N \times p}{R_{O}^{o}}$

CASE2: $\frac{v \rho L\left[R_{o}^{o}+R_{V}^{o}\right] \times N \times(1-p)}{R_{V}^{o}}$

CASE 3: $\frac{v \rho L\left[R_{V}^{V}+R_{O}^{V}\right] \times N \times[(1-p) / 3]}{R_{O}^{V}}$

CASE $4: \frac{v \rho L\left[R_{V}^{V}+R_{O}^{V}\right] \times N \times[(1-p) / 12]}{R_{V}^{V}}$

CASE 5: $\frac{v L\left[\left[R_{V}^{V}+R_{O}^{V}\right] \times N \times[(1-p) / 12]\right.}{R_{O}^{V}}$

CASE 6: $\frac{v \rho L\left[R_{V}^{V}+R_{O}^{V}\right] \times N \times[(1-p) / 12]}{R_{V}^{V}}$

The artificial immune system-based technique is responsible for search, retrieve and match the information to perform LM procedure.

In the matching process [13], the user is residing in a particular location area, and UE is trying for location registration with current base station. This update request-information message will forwarded to mobile switching centre via associated BS. The mobile switching centre performs a 
matching procedure for mobile user (within the RBS/FBS).

For each given query, matching procedure is average of self-information set of $t$ tuple $\operatorname{Sat}(\mathrm{t})$ with respect to tuples to the query. That is, matching information can be written follows.

Let $\left(\mathrm{t}, \mu_{\mathrm{r}}(\mathrm{t})\right)$ be a tuple in the extended fuzzy relation $|t|=k$ and $|\operatorname{Sat}(\mathrm{t})|=\mathrm{n}$, where $n \leq k$. Then, matching information of $\mathrm{t}, \mathrm{I}_{\text {mat }}(\mathrm{t})$, is $\mathrm{I}_{\text {mat }}(\mathrm{t})=\frac{\mathrm{n}}{\mathrm{k}}\left(\sum_{\mathrm{i}=1}^{\mathrm{n}} \mu_{\mathrm{r}}\left(\mathrm{t}_{\mathrm{i}}\right) / \mathrm{n}\right)=\left(\sum_{\mathrm{i}=1}^{\mathrm{n}} \mu_{\mathrm{r}}\left(\mathrm{t}_{\mathrm{i}}\right)\right) / \mathrm{k}$ $\mu_{\mathrm{r}}(\mathrm{t})=\operatorname{MIN}\left(\mu\left(\mathrm{t}\left[\mathrm{A}_{1}\right]\right), \ldots \ldots \ldots\left(\mathrm{t}\left[\mathrm{A}_{\mathrm{n}}\right]\right)\right)$ And $\mu\left(\mathrm{t}\left[\mathrm{A}_{\mathrm{i}}\right]\right)=\operatorname{MAX}\left(\mu\left(\mathrm{a}_{\mathrm{i} 1}\right), \ldots \ldots \ldots ., \mu\left(\mathrm{a}_{\mathrm{im}}\right)\right)$

The expected value of cost of matching is:

$C_{M A T}=\int_{0}^{\infty} C r\left\{\operatorname{MIN}\left(\begin{array}{l}\operatorname{MAX}\left(\mu\left(\mathrm{a}_{\mathrm{i} 1}\right), \ldots \ldots \ldots ., \mu\left(\mathrm{a}_{\mathrm{i} n}\right)\right) \\ , \ldots \ldots \ldots . \operatorname{MAX}\left(\mu\left(\mathrm{a}_{\mathrm{i} 1}\right), \ldots \ldots \ldots \ldots, \mu\left(\mathrm{a}_{\mathrm{im}}\right)\right)\end{array}\right) \geq t\right\} d t-\int_{\infty}^{0} \operatorname{Cr}\left\{\left(\operatorname{MIN}\left(\begin{array}{l}\left.\operatorname{MAX}\left(\mu\left(\mathrm{a}_{\mathrm{i} 1}\right), \ldots \ldots \ldots \ldots, \mu\left(\mathrm{a}_{\mathrm{i} n}\right)\right), \ldots \ldots \ldots . \mathrm{MAX}\right) \\ \left(\mu\left(\mathrm{a}_{\mathrm{i} 1}\right), \ldots \ldots \ldots ., \mu\left(\mathrm{a}_{\mathrm{im}}\right)\right)\end{array}\right) \leq t\right\} d t\right.$

Where, $\forall a_{i j} \in t(A[i])$ and $i=1, \ldots n$.

In the fetching process [14], the system will fetch the information from the RBS and FBS, we can set the range of the information from $\{0,1\}$. To fetch the information form database, we are considering a unit scale with datasets $(A)$, the $A$ of zero representing the average position of relevant documents being available inside the database at the beginning of the search process, and an $A$ of one being at the end of the search process. The parameter $A$ is then the expected proportion of documents examined in an optimal ranking if one examines all the documents up to the document in the average position of a relevant document. It is the expected available position of the relevant information, and it is scaled from zero to one. The variable $A$ is computed by noting, that documents with feature frequency $d$ are at the low end of the $A$ 
spectrum (good performance), and those with feature frequency $\bar{d}$ at the high end of the spectrum (poor performance).

The middle (average) position for each of the profiles, when they had arranged in order, is such cases $\operatorname{Pr}(\mathrm{d}) / 2$, is the average position for availability of documents with feature frequency $d$. The mean position of available information is $1-\operatorname{Pr}(\mathrm{d}) / 2$ for the documents with feature frequency $d$; that is, when the feature frequency is zero. Thus, the estimated value of $\mathrm{A}$ is:

$$
A=\operatorname{Pr}(d \mid r e l) \operatorname{Pr}(d) / 2+\operatorname{Pr}(\bar{d} \mid r e l)(1-\operatorname{Pr}(\bar{d})
$$

Using a similar technique, we find that $\bar{A}$, the A value for the worst-case ranking, is $1-A$. It is simplified algebraically to $A=\frac{1+\operatorname{Pr}(d)-\operatorname{Pr}(d \mid r e l)}{2}, \quad C_{F A T}=n A=n \times\left(\frac{1+\operatorname{Pr}(d)-\operatorname{Pr}(d \mid r e l)}{2}\right)$, where $n$ represent the number of fetched information.

The update process [15], is responsible for the update of the information in rule/fact based system. The associated cost is based on cost of reading an average sized sub-tuple multiplied by the probability of a read versus the cost of writing an average sized sub-tuple multiplied by the probability of a write-up in the database.

Based on above discussion we are remarking that, when the system observes; there are more frequent availability of large clean sub-tuples, it will make expand the clean sub-tuples buffer. The equation below formally defines and it is representing as follows.

$$
\begin{aligned}
C_{U P}= & \text { expected cost per byte of loading } \times \text { expected cost per byte of update } \\
& \times \text { Avarage number of data to be updated } \\
= & \mathrm{cL} \times \mathrm{cU} \times \operatorname{Avg}(\mathrm{D})
\end{aligned}
$$


The LM Procedure cost is the combination of location management's operational cost, database manipulation and signaling cost. The signaling cost has a major role with the user mobility. The movement of the user's can be classified as: Inter LA, Inter MSC, Inter VLR, Inter HLR, and its signaling cost can be computed as, 4, 4, 8 and 10 units, respectively [4]. The per unit signaling cost for the location management is [1].

$\mathrm{C}_{\mathrm{SIGNAL}}=\left(\begin{array}{l}\mathrm{N}_{\mathrm{MT}} \times \frac{2(\mathrm{~h}-1+\eta) v+\mathrm{T}_{\mathrm{P}}}{\mathrm{d}}+\mathrm{N}_{\mathrm{MT}} \times \mathrm{N}_{\mathrm{CN}} \times \frac{2(\mathrm{~h}-1+\eta) \varphi}{\mathrm{d}}+ \\ \mathrm{N}_{\mathrm{MT}}^{2} \times \mathrm{N}_{\mathrm{CN}} \times \frac{\chi \lambda_{\mathrm{CALL}}}{\mathrm{S}}\end{array}\right) \times \mathrm{SIZE}_{\text {DATA-PACKET }}$

The location management will be

$$
\begin{aligned}
& C_{L U}^{E x i s t i m g}=\pi_{O}^{O} \times \frac{v \rho L \times\left[R_{O}^{O}+R_{V}^{O}\right] \times N \times p}{R_{O}^{O}} \times 4 \times C_{S I G N A L}+\pi_{V}^{O} \times \frac{v \rho L\left[R_{O}^{O}+R_{V}^{O}\right] \times N \times(1-p)}{R_{V}^{O}} \times 4 \times C_{S I G N A L}+ \\
& \pi_{O}^{V} \times \frac{v \rho L\left[R_{V}^{V}+R_{O}^{V}\right] \times N \times[(1-p) / 3]}{R_{O}^{V}} \times 8 \times C_{S I G N A L}+\pi_{V}^{V} \times \frac{v \rho L\left[R_{V}^{V}+R_{O}^{V}\right] \times N \times[(1-p) / 12]}{R_{V}^{V}} \times \\
& 8 \times C_{S I G N A L}+\pi_{O}^{V} \times \frac{v \rho L\left[R_{V}^{V}+R_{O}^{V}\right] \times N \times[(1-p) / 12]}{R_{O}^{V}} \times 10 \times C_{S I G N A L}+\pi_{V}^{V} \times \frac{v \rho L\left[R_{V}^{V}+R_{O}^{V}\right] \times N \times[(1-p) / 12]}{R_{V}^{V}} \\
& \times 10 \times C_{S I G N A L}+2 C_{M A T}+2 C_{F A T}+2 C_{U P}
\end{aligned}
$$

It is the cost of location management through the traditional system; in our proposed system there will two case best case and worst cases.

Best Case: The mobile user does not make a full registration, the required information can be fetched from the RBS and FBS (information's are already available). All the required information for the location update is available in the system, and it lead to less communication 
cost, because there are only two pairs of information exchange(we are taking on pair of signal exchange is same of one unit signaling cost[1-4]).

$$
\begin{aligned}
& C_{L U}^{\text {Proposed }}(\text { Best })=\pi_{O}^{O} \times \frac{v \rho L \times\left[R_{O}^{O}+R_{V}^{O}\right] \times N \times p}{R_{O}^{O}} \times 2 \times C_{S I G N A L}+\pi_{V}^{O} \times \frac{v \rho L\left[R_{O}^{O}+R_{V}^{O}\right] \times N \times(1-p)}{R_{V}^{O}} \\
& \times 2 \times C_{S I G N A L}+\pi_{O}^{V} \times \frac{v \rho L\left[R_{V}^{V}+R_{O}^{V}\right] \times N \times[(1-p) / 3]}{R_{O}^{V}} \times 2 \times C_{S I G N A L}+\pi_{V}^{V} \times \frac{v \rho L\left[R_{V}^{V}+R_{O}^{V}\right] \times N \times[(1-p) / 12]}{R_{V}^{V}} \\
& \times 2 \times C_{S I G N A L}+\pi_{O}^{V} \times \frac{v \rho L\left[R_{V}^{V}+R_{O}^{V}\right] \times N \times[(1-p) / 12]}{R_{O}^{V}} \times 2 \times C_{S I G N A L}+\pi_{V}^{V} \times \frac{v \rho L\left[R_{V}^{V}+R_{O}^{V}\right] \times N \times[(1-p) / 12]}{R_{V}^{V}} \\
& \times 2 \times C_{S I G N A L}+2 C_{M A T}+C_{F A T}+2 C_{U P}
\end{aligned}
$$

Worst Case: The system need to collect the all required information and it leads to high update, fetching and matching cost. The singling cost (cost associated with signal exchange) of the system will be also high, because it needs to find more information for better LM technique, and its associated cost is as follows.

$$
\begin{aligned}
& C_{L U}^{\text {Proposed }}(\text { Worst })=\pi_{O}^{O} \times \frac{v \rho L \times\left[R_{O}^{O}+R_{V}^{O}\right] \times N \times p}{R_{O}^{O}} \times 4 \times C_{\text {SIGNAL }}+\pi_{V}^{O} \times \frac{v \rho L\left[R_{O}^{O}+R_{V}^{O}\right] \times N \times(1-p)}{R_{V}^{O}} \\
& \times 4 \times C_{S I G N A L}+\pi_{O}^{V} \times \frac{v \rho L\left[R_{V}^{V}+R_{O}^{V}\right] \times N \times[(1-p) / 3]}{R_{O}^{V}} \times 4 \times C_{S I G N A L}+\pi_{V}^{V} \times \frac{v \rho L\left[R_{V}^{V}+R_{O}^{V}\right] \times N \times[(1-p) / 12]}{R_{V}^{V}} \\
& \times 4 \times C_{\text {SIGNAL }}+\pi_{O}^{V} \times \frac{v \rho L\left[R_{V}^{V}+R_{O}^{V}\right] \times N \times[(1-p) / 12]}{R_{O}^{V}} \times 4 \times C_{\text {SIGNAL }}+\pi_{V}^{V} \times \frac{v \rho L\left[R_{V}^{V}+R_{O}^{V}\right] \times N \times[(1-p) / 12]}{R_{V}^{V}} \\
& \times 4 \times C_{\text {SIGNAL }}+2 C_{M A T}+C_{F A T}+2 C_{U P}
\end{aligned}
$$

\section{RESULT AND DISCUSSIONS}

To evaluate the efficiency and effectiveness of the proposed work, we are taking some initial values from [1-4]. We are assuming, the movement probability of the user $p=0.05$, number of tuples in the RBS and FBS $=1000$, number of cells in a $\mathrm{LA}=50$, Number of LA inside the $\mathrm{SA}=$ 
1000. The communication media is uniform and we are considering the number of user per LA = 1000. The average speed of the mobile user $=50 \mathrm{~m} / \mathrm{h}$. The value of $L=1000 \mathrm{~m}^{2}$.

The figure 6, shows the effect of the number of mobile users in a LA over the associated cost. The figure 6 and 7, represent the overall cost and signaling cost vs user's density in a LA, respectively. The user's density vary from 10-90/LA, the mobility probability is fixed at 0.05.The graphical observation indicates that, the traditional procedure has higher cost with respect to artificial immune based system, because of greedy technique.

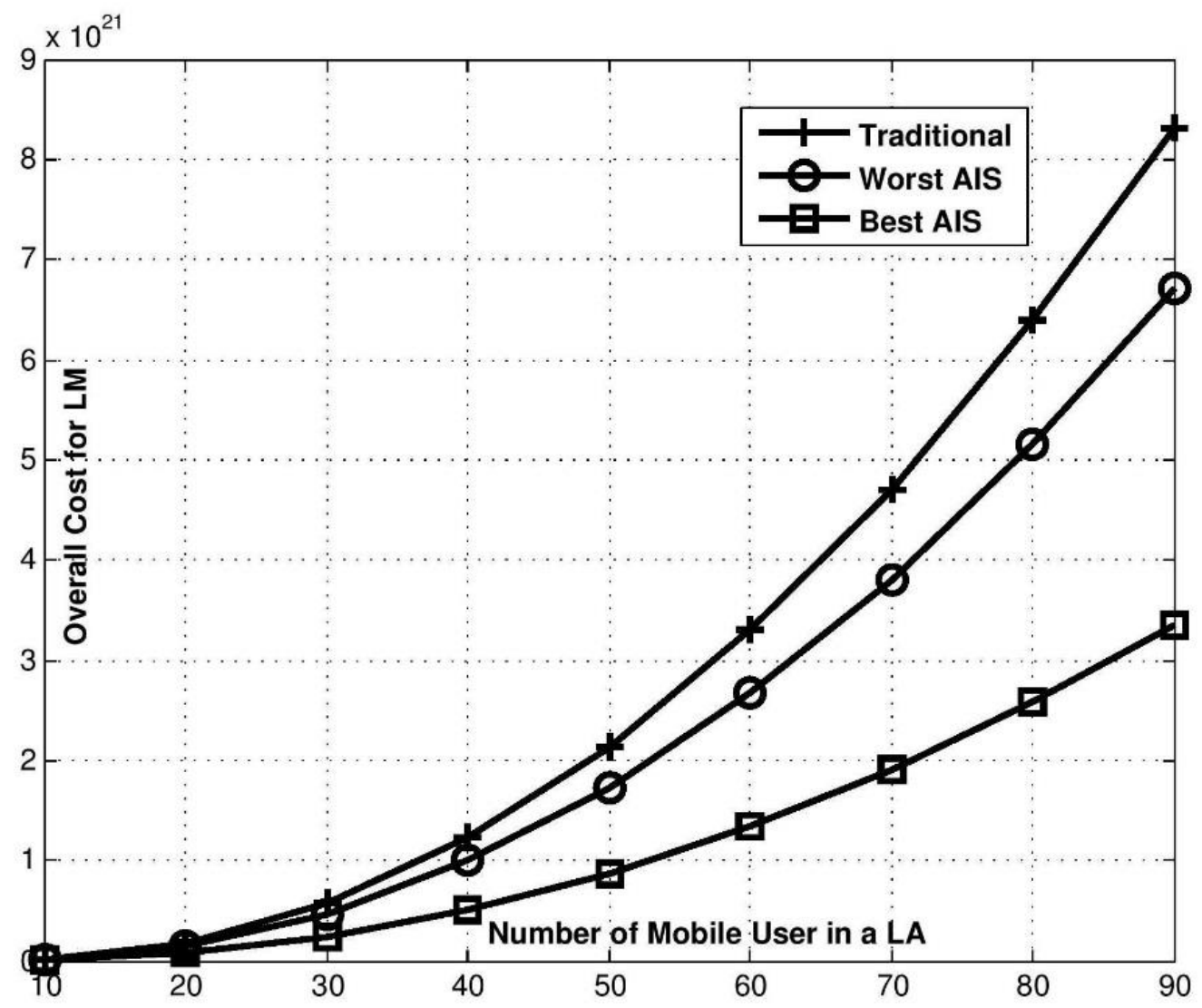

Figure 6: Overall Cost Vs User's Density 


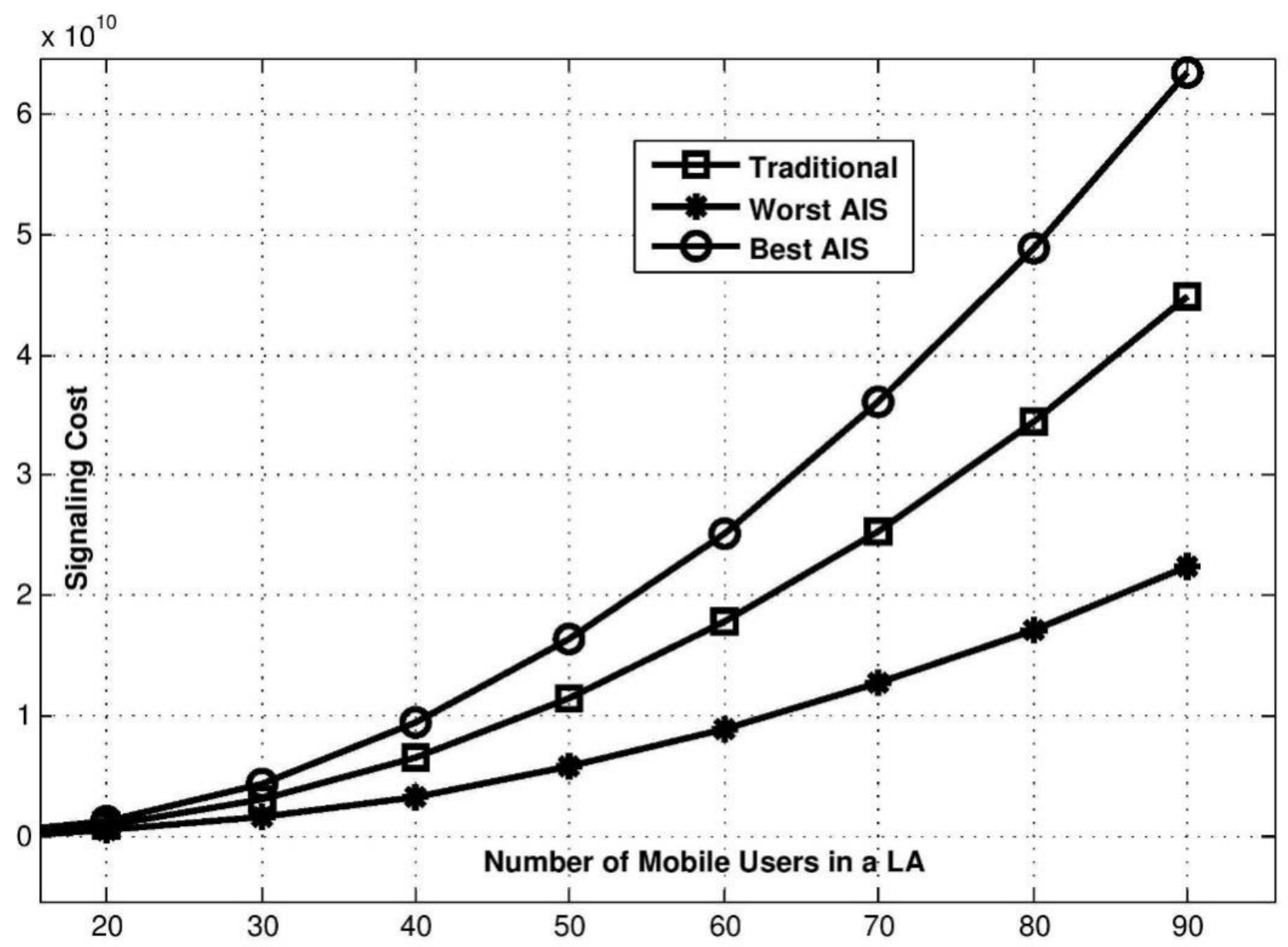

Figure 7: Signaling Cost Vs User's Density

The figure 8 shows the overall LM cost Vs user movement probability(Figure 8) and average call arrival rate (figure 9). The value of movement probability will vary from 0.05 to 0.4 and the average call rate vary from 10-90 within a LA. It has been observed that, the traditional and AIS scheme (worst case) have almost same level of growth for overall cost, but the AIS scheme with best case has remarkable reduction of the cost, because the related information for the LM not to be calculate by system (it is available in FBS and RBS). 


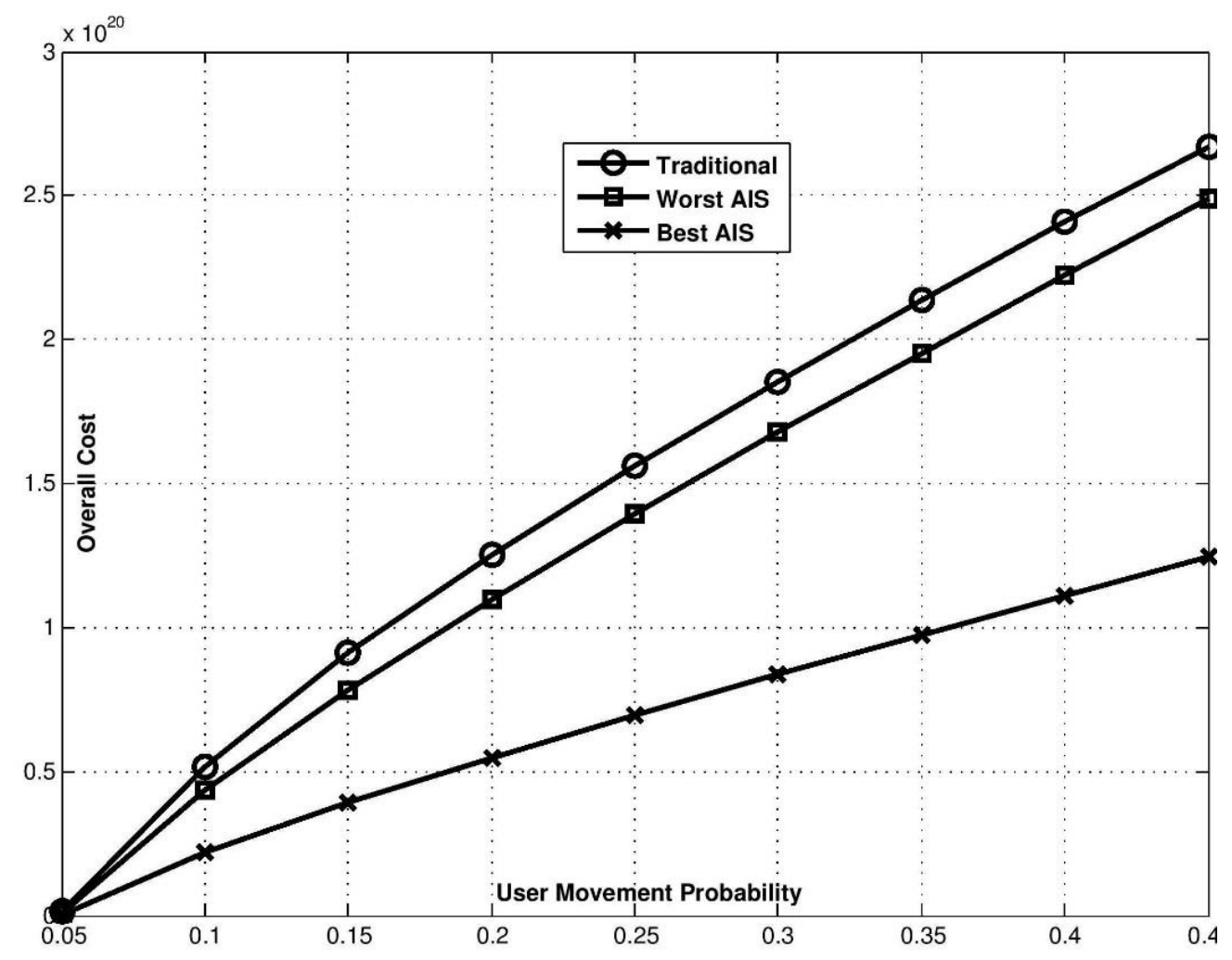

Figure 8: Overall Cost Vs User's Movement Probability

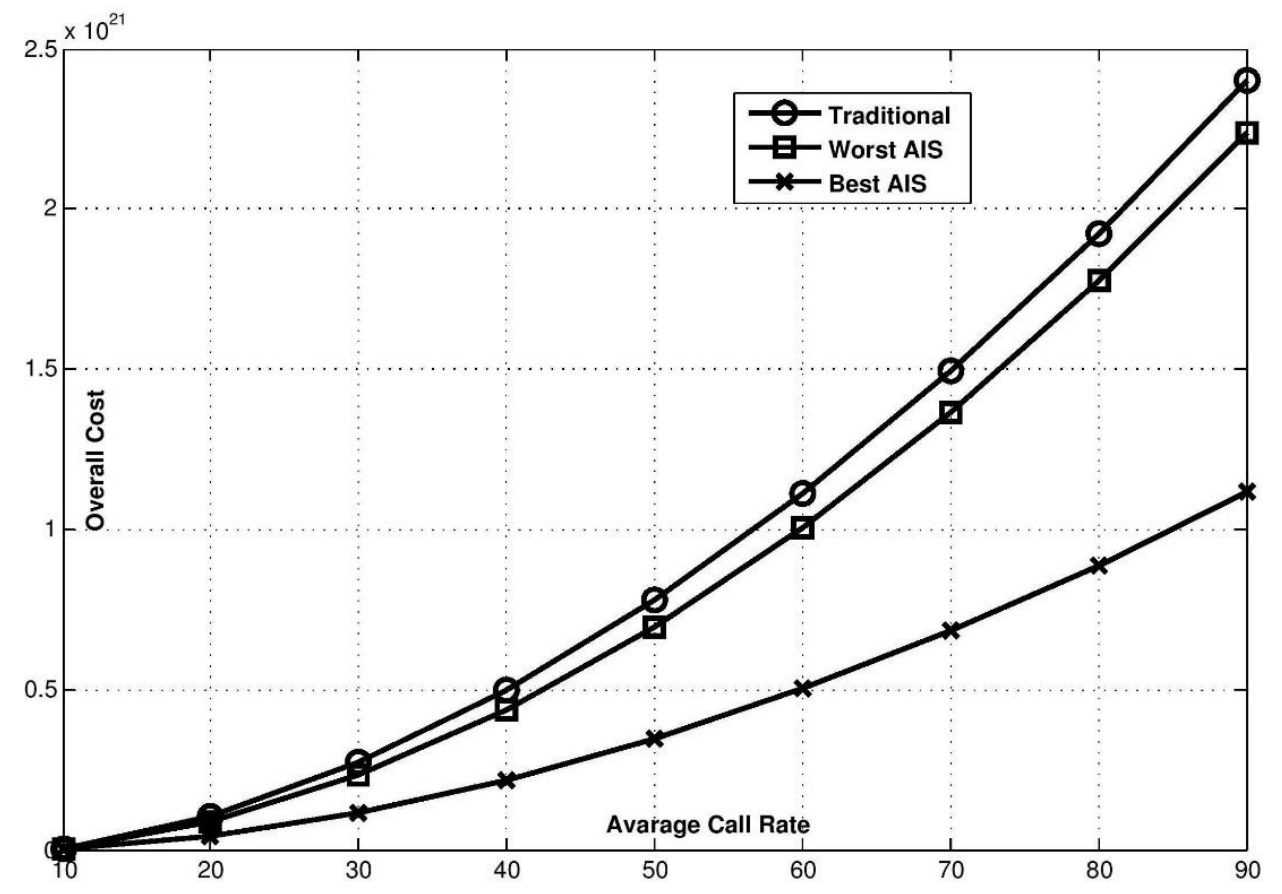

Figure 9: Overall Cost Vs Average Call 
Figure 10 represents the overall cost Vs service to user's probability inside a LA (figure 10) and overall cost Vs Call-to-Mobility (CMR) in figure 11. Here, the AIS based scheme has better result because; it calculates the related information through RBS

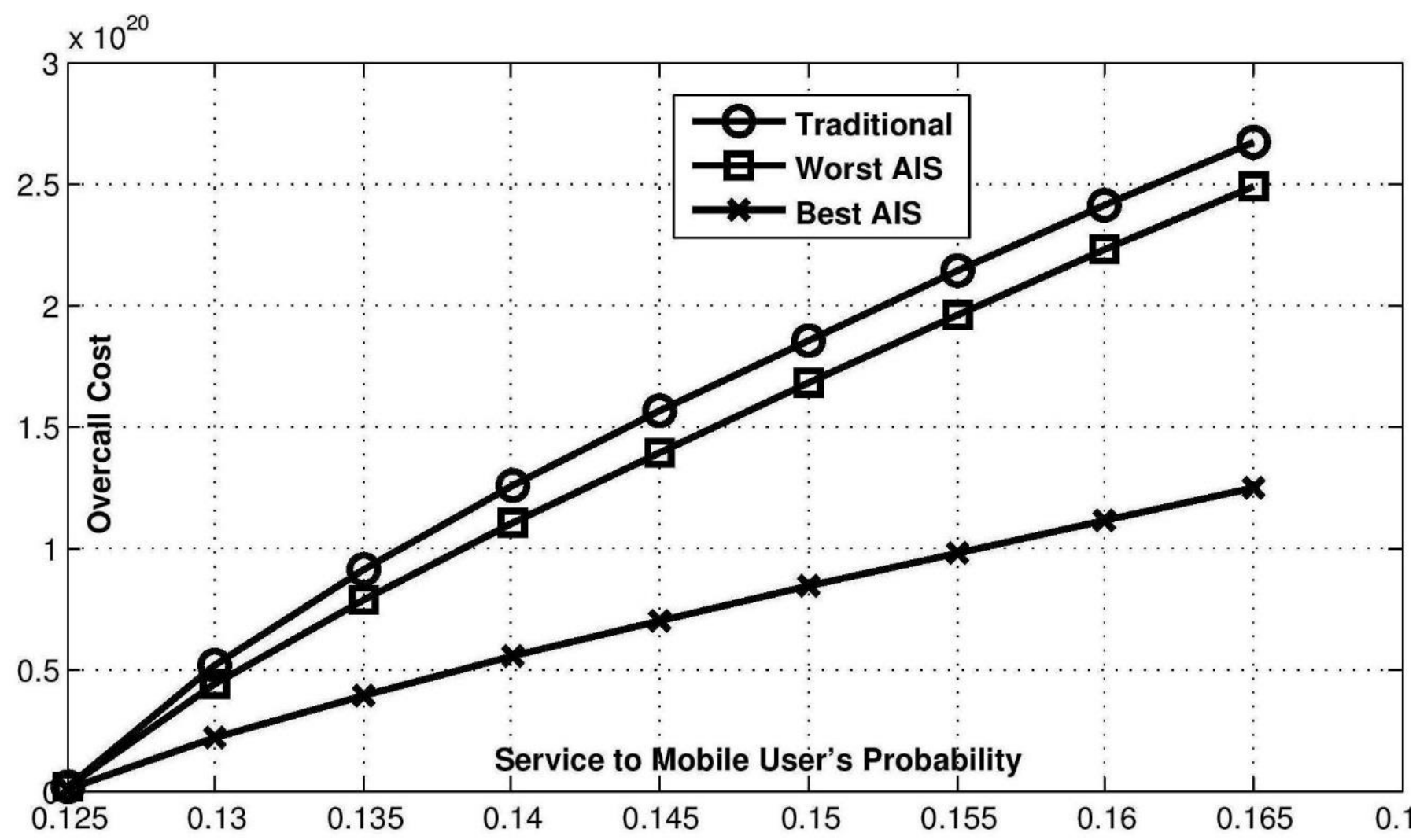

Figure 10: Overall Cost Vs Service Probability 


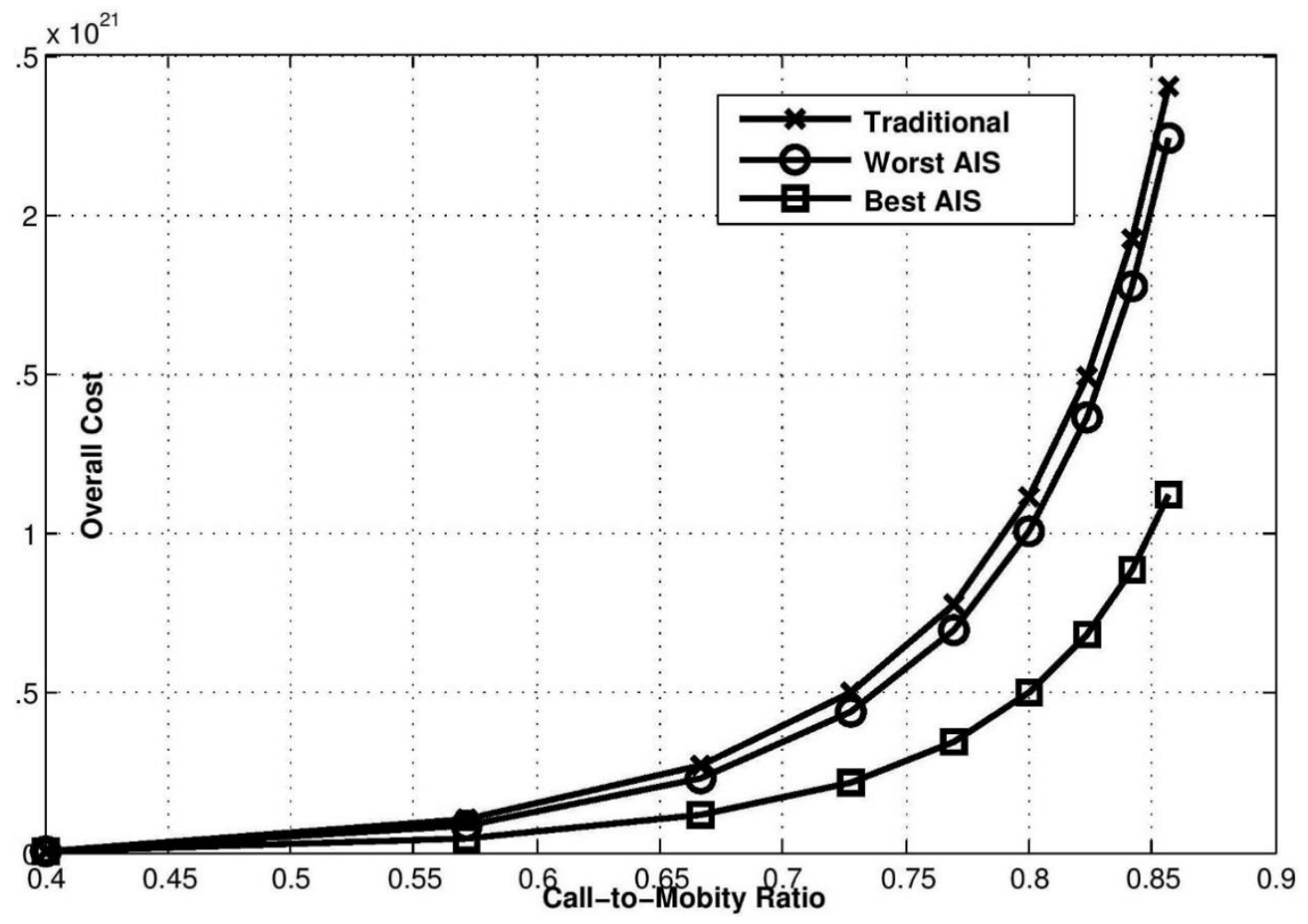

Figure 11: Overall Cost Vs Call-to-Mobility Ratio

With the help of figure 12, we can check the effectiveness of proposed scheme over the tradition scheme in the terms of hops counts to the destination users. The figure 12 shows the hop count for the LM, and figure 13 used to hop count between caller and target mobile node. 


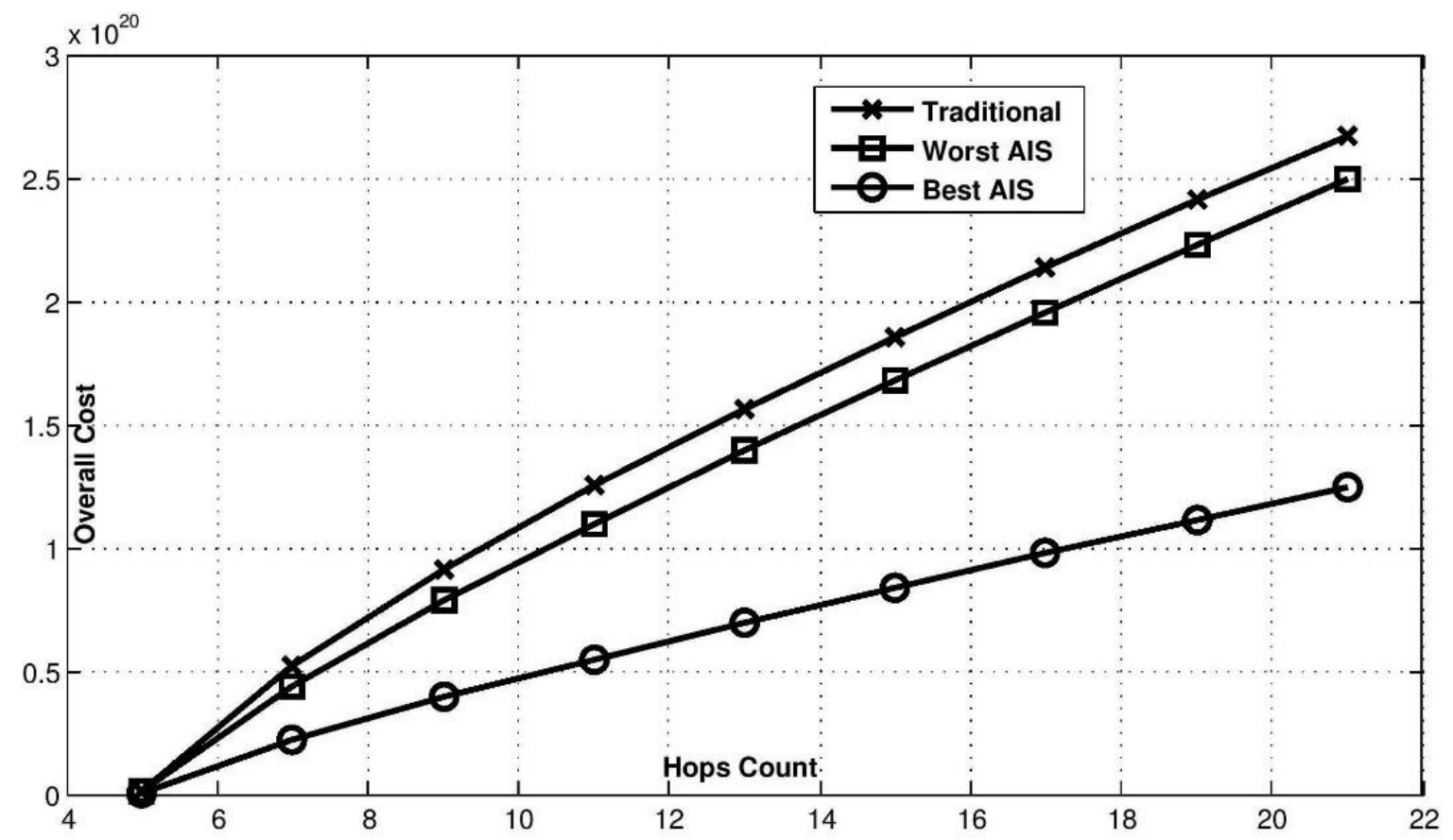

Figure 12: Overall Cost Vs Hop Count

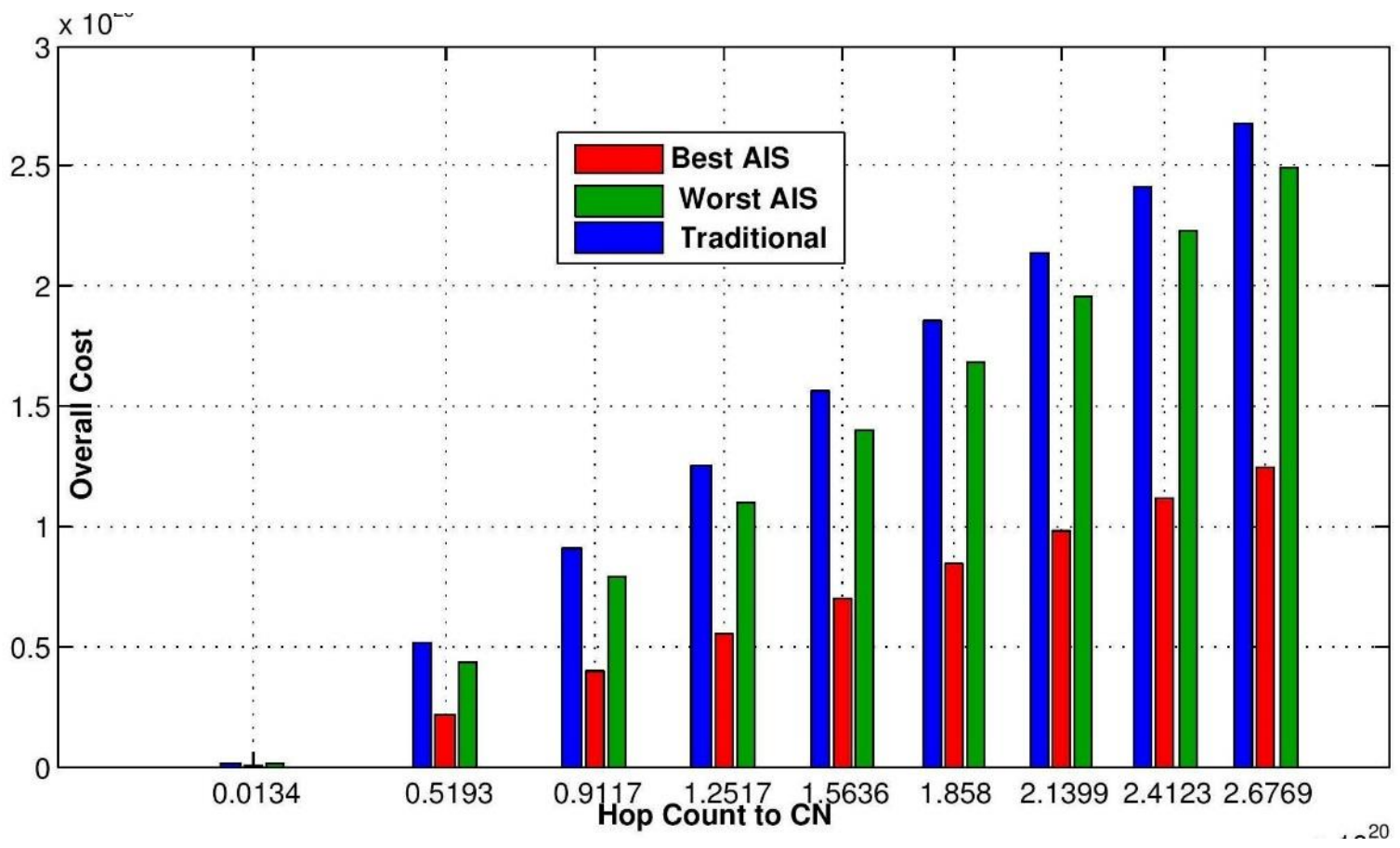

Figure 13: Overall Cost Vs Hop Count to CN 


\section{CONCLUSION}

In this paper, we proposed an artificial immune system based location management technique. We have introduced modified mobile switching center architecture, it contains rule-based, factbased system and inferring machine. The mobile switching center performs the location management based on available and associated rules/facts. After a successful location update, system will store the fact-based system for the future use. If, a new registration request arrives with same circumstance, the system will select the pre-applied method for registration and it has less communication overheads and associated cost. If, other appropriated methods are available, then the system updates the system (self-updating) and shows the adaptive and robust behavior. This proposed technique is applicable for inter and intra domain (MSC/HLR/VLR) movement of UE. Finally, the effectiveness of proposed system being check compared with the traditional 3G LM scheme and has sufficient improvement.

\section{REFERENCES}

[1] S. K. Biswash, C. Kumar, "An efficient metric-based (EM-B) location management scheme for wireless cellular networks" Journal of Network and Computer Applications, vol 34, pp 2011-2026, 2011.

[2] S. K. Biswash, C. Kumar, "An Index-Based Location Management Scheme for PCS Network" Wireless Personal Communications, vol69., pp 1597-1614, 2013.

[3] Reza Rahdar, Jerrell T. Stracener, and Eli V. Olinick, "A Systems Engineering Approach to Improving the Accuracy of Mobile Station Location Estimation”, IEEE Systems Journal, vol. 8, pp 14-22, 2014.

[4] P. K. Mishra, S. Pandey and S. K. Biswash, "Efficient Resource Management by Exploiting D2D Communication for 5G Networks," in IEEE Access, vol. 4, no. , pp. 9910-9922, 2016.

[5] F. Dressler, O. B. Akan, “A survey on bio-inspired networking” Computer Networks” vol 54 pp 881-900, 2010.

[6] K. Manjappa, R. M. R. Guddeti, "Mobility aware-Termite: a novel bio inspired routing protocol for mobile adhoc networks", IET Networks vol 2, pp 188-195, 2013

[7] Yuh-Shyan Chen, Chih-Shun Hsu, Hau-Kai Lee, "An Enhanced Group Mobility Protocol for 6LoWPAN-Based Wireless Body Area Networks”, IEEE Sensors Journal, vol 14, pp 797-807, 2014. 
[8] Xian Wang, Xianfu Lei, Pingzhi Fan, Rose Qingyang Hu, Shi-Jinn Horng, “Cost Analysis of Movement-Based Location Management in PCS Networks: An Embedded Markov Chain Approach", IEEE Transactions On Vehicular Technology. 2014; 1886-1902.

[9] Yinan Li and Ing-Ray Chen, "Mobility Management in Wireless Mesh Networks Utilizing Location Routing and Pointer Forwarding”, IEEE Transactions On Network And Service Management. Vol 9, pp 226- $239,2009$.

[10] Li Feng, Qinglin Zhao, Hanwen Zhang, "Location management based on distance and direction for PCS networks", Computer Networks, vol 51, pp 134-152, 2007.

[11] Muhammad Younas, Irfan Awan, "Mobility Management Scheme for Context-Aware Transactions in Pervasive and Mobile Cyberspace”, IEEE Transactions On Industrial Electronics, vol 60, pp 1108-1115, 2013.

[12] Miguel Rocha, Rui Mendes, Orlando Rocha, Isabel Rocha, Eugénio C. Ferreira, “Optimization of fed-batch fermentation processes with bio-inspired algorithms", Expert Systems with Applications, vol 41, pp2186-2195, 2014.

[13] Ding-An Chiang, Nancy P. Lin, and Chien-Chou Shis, "Matching Strengths of Answers in Fuzzy Relational Databases", IEEE Transactions On Systems, Man, And Cybernetics-Part C: Applications And Reviews, vol 28, pp476-481, 1998.

[14] Robert M. Losee and Lewis Church Jr, "Information Retrieval with Distributed Databases: Analytic Models of Performance", IEEE Transactions On Parallel And Distributed Systems, vol 15, pp18-27, 2008.

[15] Zhen He, Prakash Veeraraghavan, "Fine-grained updates in database management systems for flash memory", Information Sciences, vol 179, pp 3162-3181, 2009.

[16] R.J. Kuo, S.Y. Hung, W.C. Cheng, "Application of an optimization artificial immune network and particle swarm optimization-based fuzzy neural network to an RFID-based positioning system", Information Sciences vol 262, pp78-98, 2014.

[17] YanfeiZhong andLiangpei Zhang, "Sub-pixel mapping based on artificial immune systems for remote sensing imagery", Pattern Recognition, vol 46, pp 2902-2926, 2014.

[18] Xian Wang, Pingzhi Fan, Jie Li, Yi Pan, "Modeling and Cost Analysis of Movement-Based Location Management for PCS Networks With HLR/VLR Architecture, General Location Area and Cell Residence Time Distributions", IEEE Transactions On Vehicular Technology.vol 57, pp 3815-3831, 2008.

[19] Feng Xia, Xuhai Zhao, Jianhui Zhang, Jianhua Ma, Xiangjie Kong, "BeeCup: A bio-inspired energy-efficient clustering protocol for mobile learning”, Future Generation Computer Systems, vol 37,pp 449-460, 2014.

[20] M. Daoui, A. M'zoughi, M. Lalam, M. Belkadi, R. Aoudjit, "Mobility prediction based on ant system", Computer Communication, vol 31, pp 3090-3097, 2008.

[21] Kin K. Leung, Yonatan Levy, "Global Mobility Management by Replicated Databases in Personal Communication Networks,"IEEE Journal on Selected Areas in Communications, vol 15, pp 1582 - 1596 , 1997.

[22] Weiwei Zhang, Gary G. Yen, Zhongshi He, "Constrained Optimization via Artificial Immune System", IEEE Transactions On Cybernetics, vol 14, pp 185-198, 2014.

[23] Leonardo de Mello Honório, Armando M. Leite da Silva, Daniele A. Barbosa, “A Cluster and Gradient-Based Artificial Immune System Applied in Optimization Scenarios", IEEE Transactions On Evolutionary Computation, vol 16, pp 301-318, 2012. 
[24] GrzegorzDudek, "An Artificial Immune System for Classification with Local Feature Selection", IEEE Transactions On Evolutionary Computation. Vol 16, pp 847-860, 2012.

[25] A. K. Shukla, C. K. Jha, N. Saxena and S. K. Biswash, "The analysis of AODV, based on mobility model," 2013 3rd IEEE International Advance Computing Conference (IACC), Ghaziabad, 2013, pp. 440-443.

[26] Ghulam Abbas, Bandwidth Price Estimation for Scalable and Responsive Rate Control, Journal of Interconnection Networks, September 2016, Vol. 16, No. 03n04.

[27] Xiaonan Wang, Huanyan Qian, A Mobility Handover Scheme for IPv6-Based Vehicular Ad Hoc Networks, Wireless Personal Communications, Volume 70, Issue 4, pp 1841-1857, 2013.

[28] Sanjay Kumar Biswash, Chiranjeev Kumar, The Metric and Cache-Based (MC-B) System for Location Management in Wireless Cellular Networks, Wireless Personal Communications Volume 82(2015)pp 569-593 